\title{
Acquisition Integration Models: How Large Companies Successfully Integrate Startups Peter Carbone
}

\author{
"In all affairs it's a healthy thing now and then to hang $a$ " \\ question mark on the things you have long taken for \\ granted.
}

Bertrand Russell

Author, Mathematician, and Philosopher (1872-1970)

\begin{abstract}
Mergers and acquisitions (M\&A) have been popular means for many companies to address the increasing pace and level of competition that they face. Large companies have pursued acquisitions to more quickly access technology, markets, and customers, and this approach has always been a viable exit strategy for startups. However, not all deals deliver the anticipated benefits, in large part due to poor integration of the acquired assets into the acquiring company. Integration can greatly impact the success of the acquisition and, indeed, the combined company's overall market success.
\end{abstract}

In this article, I explore the implementation of several integration models that have been put into place by a large company and extract principles that may assist negotiating parties with maximizing success. This perspective may also be of interest to smaller companies as they explore exit options while trying to ensure continued market success after acquisition. I assert that business success with acquisitions is dependent on an appropriate integration model, but that asset integration is not formulaic. Any integration effort must consider the specific market context and personnel involved.

\section{Introduction}

When large companies wish to bring new technology to market, increase their portfolio capability to address broader customer opportunities, or access new customers or market segments, their need to move quickly drives them to consider acquiring the assets of other companies. The target of acquisition, typically a startup, may have outstanding technology and a wish to exit stand-alone operation in favour of being acquired. Their motivation may be to leverage a larger company's capabilities, such as cash for growth, access to channels, and brand association. The combination of these complementary motivations may seem to provide a strong force in the market, however, a strong commercial outcome depends on successful integration to realize the consolidated potential of any deal. Many acquisitions that looked promising during the business case phase do not deliver to expectation, in part due to the implementation challenges.
Based on a several first-hand acquisition experiences, I have observed that the majority of the discussion preceding the close of a deal is often focused on the value of the technology being acquired, the fit to a customer's solution, sales projections, market valuation, and potential roles for the senior leaders in the acquiring company. The most successful transactions that I have been involved with also had a clear strategy for the assimilation of the new company into the acquired company, one that fueled growth of the strongest assets.

\section{Transactions Selected for Examination}

Over an eight year period, Nortel (http://wikipedia.org /wiki/Nortel) made more than 20 acquisitions of companies to improve its market/competitive position and accelerate technology availability. This article will examine six of these transactions (Table 1), selected based on the author's personal involvement. These selected transactions illustrate some of the characteristics 


\section{Acquisition Integration Models}

\section{Peter Carbone}

Table 1. Summary of selected Nortel acquisitions

\begin{tabular}{|c|c|c|c|c|}
\hline Company & Year & Cost & Description & Nortel's Motivation \\
\hline $\begin{array}{l}\text { Aptis } \\
\text { Comm }\end{array}$ & 1998 & $\sim \$ 290 \mathrm{M}$ & $\begin{array}{l}\text { Remote-access data networking } \\
\text { startup }\end{array}$ & $\begin{array}{l}\text { Replace a partner's weaker } \\
\text { product to achieve technology } \\
\text { and market leadership }\end{array}$ \\
\hline Architel & 2000 & $\sim \$ 395 \mathrm{M}$ & Network management company & $\begin{array}{l}\text { Fill gaps in overall network } \\
\text { management portfolio }\end{array}$ \\
\hline $\begin{array}{l}\text { Bay } \\
\text { Networks }\end{array}$ & 1998 & $\sim \$ 9.1 \mathrm{~B}$ & Large data networking company & $\begin{array}{l}\text { Accelerate a competitive entry to } \\
\text { new market segment with } \\
\text { leadership technology, market } \\
\text { access, and customer base }\end{array}$ \\
\hline Cambrian & 1998 & $\sim \$ 300 \mathrm{M}$ & Metro optical start-up & $\begin{array}{l}\text { Fill portfolio technology gap } \\
\text { quickly and secure new platform }\end{array}$ \\
\hline Clarify & 1999 & $\$ 2.1 \mathrm{~B}$ & Front office CRM solutions & Broaden enterprise portfolio offer \\
\hline Shasta & 1999 & $\sim \$ 340 \mathrm{M}$ & $\begin{array}{l}\text { Service } \mathrm{g} / \mathrm{w} \text { and policy } \\
\text { management edge router }\end{array}$ & $\begin{array}{l}\text { Enter new growth market for } \\
\text { services gateways and } \\
\text { applications/services }\end{array}$ \\
\hline
\end{tabular}

of the different integration models being used and will be examined based on their impact on performance.

\section{Models of Integration}

Different models of integration are characterized based on how the newly acquired assets are leveraged by the acquirer. Figure 1 illustrates four types of integration that can be differentiated along two dimensions: i) the form of integration used and ii) the target organization for integration. The form of integration considers whether resources are consolidated in the buyer's or seller's company; the other dimension considers whether the combined entity remains as a standalone unit or is absorbed into the acquiring company's units.

1. The "Cross-Leverage" model leaves the acquisition as a separate business unit, but merges the technology and people into the main company. Bay Networks was a large company and, after being acquired, was folded into the existing data business within Nortel at the executive level. It then underwent portfolio rationalization and integration across the new, larger data networking unit, being fully assimilated over time. This is the default model when the acquired company is very large or has overlapping portfolio elements that must be rationalized.
2. The "New Bet" model turns an acquisition into a new, standalone business unit within the company to pursue a new market segment. Shasta was a startup that had a unique value proposition at the time. They offered a services gateway based on routing technology that was not easily addressable by the market leader, Cisco, due to its architecture. Shasta was set up as a new, standalone "applications business unit" within the larger company and was chartered to lead in this new applications space by leveraging Nortel's brand, customer base, and manufacturing leverage. In theory, this model should assist in entering a new market segment; however the new entity must overcome many challenges, such as the acquiring company's lack of brand value in a new space, different business processes, and unwanted "help" from the acquiring company.

3. The "Top Up" model breaks up the acquired entity into portfolio elements and consolidates it into the acquiring company. Architel's portfolio elements were consolidated with the Nortel portfolio elements and the product managers and technology people moved to join Nortel organizations. Clarify was split between the Enterprise and Service Provider divisions within Nortel and was consolidated within these units. This model works well to accelerate a successful internal business 


\section{Acquisition Integration Models}

Peter Carbone

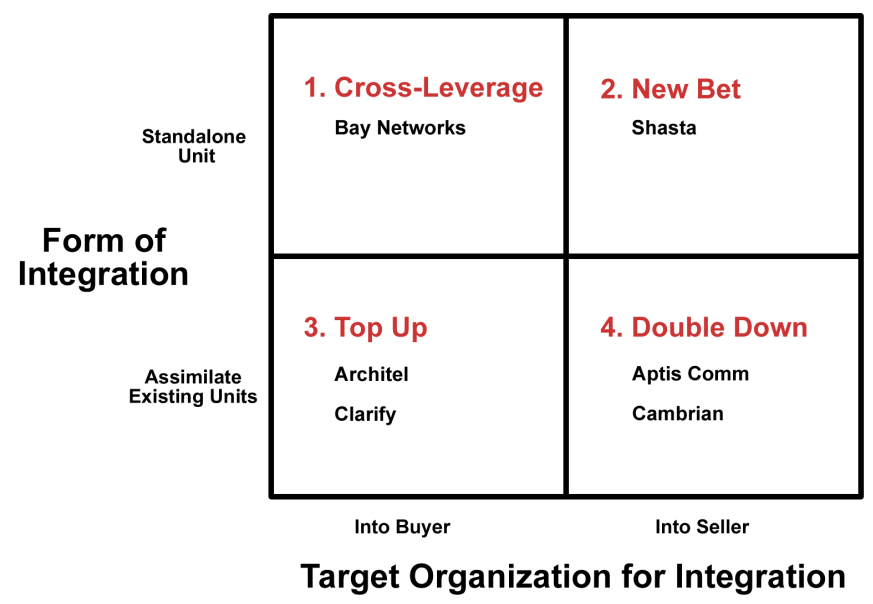

Figure 1. Four models of acquisition integration

unit by providing it with additional resources and filling gaps more quickly than can be done organically.

4. The "Double Down" model consolidates both companies' assets into the acquired company. In the case of Aptis, all Nortel and Bay Networks remote access technology and associated sales teams were moved to Aptis and the President of Aptis took on the larger responsibility for the development and revenue targets of the combined portfolio. This model works best when the acquired company has the market momentum, brand, customer base, or channel, and when it also has an effective leadership team.

The motivation for using one model over another appears to consider the following:

1. The acquiring executive's preference for structuring and organizing the new assets, often based on the available internal talent

\section{What is possible giving the size of the acquisition}

3. The decision to focus on business results (e.g., market share, revenue) or technology results (e.g., platforms, portfolio elements)

Each of these four models had some strengths and weaknesses, as will be discussed in the following section.

\section{Implementation Discussion}

The most successful transactions, as measured by market or revenue growth, were the ones that maintained a strong business focus after the deal closed, rather than a strong technology focus. By reviewing these six examples, the key attributes that contributed to success or failure can be distilled.

Aptis grew to become the market share leader in its category, despite competition from large, dominant players, such as Cisco and Alcatel. Aptis had developed high-performance technology, but were struggling to penetrate the market. The following factors impacted their success:

1. Consolidation of smaller capacity remote access platforms with Aptis and provision of a clear and single focus for remote access in the company. This avoided the inevitable platform battles that would have emerged between different organizations if they had not been consolidated.

2. Consolidation of associated sales forces. This provided access to large customers (Regional Bell Operating Companies in this case) and avoided go-to-market conflict.

3. Setting of aggressive revenue targets (beyond what Aptis thought possible). This was a clear and shared goal for the entire team and made the Aptis unit a core contributor to the success of the overall Nortel division.

4. Transfer of an experienced R\&D leader to Aptis, who was able to tap the Nortel technology portfolio quickly for required assets and manufacturing capability. This person worked well as an "employee" of the Aptis, successfully eliminating an "us versus them" mindset.

5. Appointment of the President of Aptis as the clear leader for the consolidated business.

6. Provision of required investment to develop and ship the competitive product.

With limited distractions and a clear focus, this became one of Nortel's most successful transactions in that it exceeded its acquisition business case.

Cambrian grew to provide a successful platform and portfolio for Nortel, and it held a market leadership pos- 


\section{Acquisition Integration Models}

\section{Peter Carbone}

ition for several years. The company had developed and delivered a technology capability in advance of most competitors and were struggling with scaling to demand. Following its acquisition by Nortel, Cambrian was provided with:

1. A senior Nortel leader to co-lead the business unit. The Nortel leader provided access to R\&D and manufacturing, as well as the service provider market. The Cambrian leadership remained focused on enterprise opportunities, and by working well together, they were able to reach a leadership position.

2. Clarity around Cambrian's positioned as the company's key bet in the metro-optical space, including ambitious targets that were key to the success of the overall business unit.

3. Investment to grow and evolve the portfolio and platform.

4. Access to Nortel's technology and manufacturing capability.

5. Access to Nortel's customer base and sales team.

Cambrian was also a successful transaction. As with the Aptis acquisition, the decision made was to add capability and fuel to the unit that was focused and was gaining success. By doing this, Nortel avoided having to train a new leadership team and address the natural concerns that acquired companies have about being "taken over". The key was to rapidly fuel a winning business and provide it with a compatible joint leadership team.

The "new bet" on Shasta was less successful. Although they had excellent technology and market position for their target service-edge market, the startup leadership team did not know how to leverage Nortel effectively and had little respect for the Nortel team, seeing the larger company as a drag on their nimbleness and momentum. Table 2 summarizes the factors that impacted the success of this acquisition.

The "top up" of the network management portfolio with Architel worked as expected. The Architel team saw the value in leveraging Nortel's technology and sales to further penetrate the market, and this contributed to the new unit's aligned objectives. These efforts benefited greatly from a compatible management team at the director level. The service provider portion of Clarify was less successful because the core technology team was retained in a different unit that had different priorities. This arrangement slowed the implementation changes required to fit the offers to the respective markets. Because the Clarify team was artificially split between Nortel units, they retained allegiance to two masters (their old core team and their new masters: Nortel), which negatively impacted performance.

The Cross-Leverage model used with Bay Networks was difficult to implement due to the relative large sizes of the two merging organizations and the overall complex-

Table 2. Factors that impacted the success of the Shasta acquisition by Nortel

\begin{tabular}{|c|c|}
\hline Contributing Factors & Detracting Factors \\
\hline $\begin{array}{l}\text { - Clear positioning as Nortel's offer in the } \\
\text { applications space } \\
\text { - The autonomy to pursue the sector with } \\
\text { their own sales force, which they were } \\
\text { able to do very quickly } \\
\text { - Some liaison resources were provided to } \\
\text { bridge back and provide access to Nortel. } \\
\text { - Investment to enhance the product offer } \\
\text { - Appointment of the Shasta President as } \\
\text { leader of the new applications unit }\end{array}$ & $\begin{array}{l}\text { - Internal teams pursued Shasta as a source for an IP } \\
\text { platform, which made the priorities less clear and } \\
\text { distracted the team from their focus on services. } \\
\text { - The original executive sponsor was reassigned, } \\
\text { allowing the original business case to be } \\
\text { dynamically changed to reflect platform investments } \\
\text { that did not help secure sector leadership. } \\
\text { - Not all technology in the services space was } \\
\text { consolidated, causing internal teams to bid against } \\
\text { each other in customer deals. } \\
\text { - The Shasta team did not know how to leverage } \\
\text { Nortel's other assets and capabilities. }\end{array}$ \\
\hline
\end{tabular}




\section{Acquisition Integration Models}

\section{Peter Carbone}

ity of the portfolio and market. Time was not an ally, as competitors were able to target various portfolio elements and reduce overall penetration. This put pressure on development budgets, ultimately resulting in program cancellations. There was drift in focus due to the multitude of potential opportunities, and the integration into the Nortel unit required the two teams to spend time educating each other on capabilities and strategies. The slow integration prevented this acquisition from performing to its potential.

\section{Increasing the Potential for Success}

The question is always how to maximize the probability of success with any M\&A activity. Based on experience with these transactions, there are five key principles that, if followed, would increase the probability of any acquisition success. Many of these can be derived with common sense, however, based on the variable success in the transactions examined here, more attention should be paid to them.

1. Maintain a business focus over the business case period used to justify the transaction. In several cases, the original business case used to justify the acquisition was overlooked due to changes in leadership, market conditions, or perceived momentum. This can be avoided by having the transaction's sponsoring executive continue to be actively involved and accountable to deliver the original business plan (or justify its enhancement), at least until it can be determined that the market momentum promised is on track for delivery.

2. Accommodate the size of the acquisition in the integration plan, with a focus on ensuring the business plan is implemented quickly. Small acquisitions proceed more quickly into integration than larger ones, thereby enhancing the performance of the business plan. For large acquisitions, the company must hasten any "cross-leveraging" integration to reduce the vulnerability of the new entity to competition. From the examples above, this goal can be accomplished by rapidly assimilating the portfolio elements and associated people into the unit.

3. Ensure compatibility at the level of working-team management, not just the executive level. Executives of the acquired company are always a focus in a transaction, however, in some of the transactions examined here, some of the key management people were moved into organizations with little consideration for their fit.
This results in friction, delays, and unproductive politics. This potential problem was addressed in other transactions by assessing the compatibility of the working-level team leaders and accommodating their requirements for success (e.g., clearly delineated responsibilities, joint performance objectives).

4. Bet on the team that has momentum in the market. It seems obvious, however, it is easy for a master-slave relationship develop. To avoid this potential problem, the business case should reflect the resulting organizational model and associated performance so that "fuel" can be quickly added" to the asset that has momentum.

5. Ensure absolute clarity around the new purpose, mission, and business objectives of the acquisition. As is often the case, a transaction changes the scope, market access, or potential for the new combined unit. Often, the acquired company wants to continue with the status quo because this approach helped them achieve a success exit. Alternatively, the buyer may want to fold the assets into its current model. As in the cases examined above, the most successful integrations establish clear leadership and business objectives, and they provide the new leader with the appropriate tools to do the job.

Although selecting a model is not formulaic, in addition to putting appropriate business discipline around the transaction, betting on the team with momentum has a high impact. This involves consolidating with the new player (as seen with Aptis) or strengthening internal momentum (as seen in the Architel network management case). The team that best knows how to use the assets will have higher potential for market leadership.

In hindsight, the Shasta acquisition might have resulted in better performance had principle 5 been applied along with the Double Down model, thereby consolidating the smaller capacity VPN portfolio with the acquired company.

\section{Conclusion}

The requirement for choosing an appropriate integration model is not a surprise, but too often it is pushed aside during the excitement of the chase. Although M\&A is a key tool for driving competitiveness, additional focus must be placed on integrating the assets of the companies to realize the anticipated value. As with most processes, success is based on people and the 


\section{Acquisition Integration Models}

\section{Peter Carbone}

speed of execution. Success is easier to achieve with small acquisitions, but there is no reliable, formulaic model.

The five principles identified here, by looking at a subset of Nortel's acquisitions, highlight the application of common business principles to the M\&A space, including measuring results against a plan, making decisions quickly, clarifying purpose, supporting a winner, and ensuring strong team performance.

Understanding the characteristics of these different integration models and their success factors may allow a small company to promote its value and integration differently and avoid traps that can destroy the value of an acquisition. An acquisition is a material change, and it requires change in management structure, which is always difficult and bring with it potential benefit and risk. Principle 4 - betting on the team that has momentum in the market - is often the hardest for a company to do; however, allowing new players that have market momentum to drive the business is a foundation of any successful acquisition.

\section{About the Author}

Peter Carbone is a successful executive known for his thought leadership, business acumen, and technology leadership. He is often called on to address new business and technology challenges. Peter is a pathfinder with a track record of creating innovative solutions, strategically managing technology and innovation, successfully launching and running new businesses, and leading business development initiatives. Peter has held CTO, R\&D, and senior business positions in several high-tech companies, and he has led or been directly involved with several technology company acquisitions. Peter has been engaged as technical advisor to startups, is part of the faculty of an entrepreneur development program that has created $>100$ new companies, and has been on the boards of US-based Alliance for Telecommunications Industry Solutions (ATIS) and Coral CEA. He is past Vice-Chair of the Executive Committee of the Information Technology Association of Canada (ITAC) and Chair of an ITAC committee, which is focused on the Global Competitiveness of Canada's Knowledge Economy.

Citation: Carbone, P. 2011. Acquisition Integration Models: How Large Companies Successfully Integrate Startups. Technology Innovation Management Review. October 2011: 26-31. (cc) BY 